\title{
Effect of Steel Composition on Iron Dissolution in Molten Zinc and Development of Fe-Zn Phases on Steel Surface
}

\author{
R. MISHRA and Monojit DUTTA \\ Research and Development, Tata Steel, Jamshedpur-831001, India. \\ E-mail: rajiv.mishra@tatasteel.com, monojitdutta@tatasteel.com
}

(Received on March 19, 2007; accepted on August 1, 2007)

\begin{abstract}
The effect of steel composition on iron solubility in molten zinc and coating microstructure was studied by immersing test coupons of four different steel grades in zinc bath for 20 min at $470^{\circ} \mathrm{C}$. The amount of iron dissolved in the molten zinc depends upon the steel composition. The coating was characterized by energy dispersive spectroscopy, X-ray diffraction and galvanostatic methods. The coating consists of mainly $\zeta$ (zeta) and $\delta$ (delta) phases along with zinc layer at the top, irrespective of the steel composition. The presence of a thin layer of gamma phase has also been confirmed by XRD and galvanostatic analysis. However, the proportion and distribution of the coating phases varies with the steel chemistry.
\end{abstract}

KEY WORDS: iron dissolution; hot-dip galvanizing; iron zinc alloys.

\section{Introduction}

Hot dip galvanizing of steel strip is carried out in molten zinc bath maintained at about $460^{\circ} \mathrm{C}$. As soon as the strip enters the liquid zinc bath, iron starts dissolving. At the galvanizing temperature, iron atoms have a strong affinity toward zinc and various $\mathrm{Fe}-\mathrm{Zn}$ intermetallics may develop. ${ }^{1,2)}$ The $\mathrm{Fe}-\mathrm{Zn}$ interface is not in equilibrium at the time of entry of the strip. Even if the bath is saturated with iron, dissolution of iron from the strip surface continues during the initial moments after immersion. Thus a local supersaturation is attained in the vicinity of the strip, where a metastable equilibrium exists. However, to satisfy the final equilibrium of the zinc bath, the supersaturation in iron leads to the formation of a continuous layer on the strip surface, in equilibrium with the bath. ${ }^{3,4)}$

In commercial galvanizing lines, a small amount of aluminum is added. Iron has stronger affinity toward aluminum compared to zinc, and a thin $\mathrm{Fe}-\mathrm{Al}-\mathrm{Zn}$ inhibition layer is formed on strip immediately after it enters the zinc bath. As the name suggests, the inhibition layer inhibits the dissolution of iron and thus the rapidity of $\mathrm{Fe}-\mathrm{Zn}$ reactions is controlled. The inhibition layer finally helps in developing the desired coating structure. In galvanizing, a thick inhibition layer is desired to obtain pure zinc layer at the top. A thinner layer is preferable in galvannealing so that the inhibition layer can break open during post galvanizing annealing treatment and desired $\mathrm{Fe}-\mathrm{Zn}$ phases can form. ${ }^{2,4)} \mathrm{A}$ control over the formation of inhibition layer during hot dipping, and over its breakdown during galvannealing is very important to produce the optimum coating structure.

Therefore the dissolution of iron in the bath, apart from the presence of aluminum, plays an important role in the development of inhibition layer, and thereby the final coat- ing phases. Some studies have been done in last two decades on the dissolution of iron in molten zinc bath based on thermodynamic, kinetic and experimental analysis. According to Tang, ${ }^{4)}$ Fe dissolution is a three step phenomenon: separation of Fe atoms from strip surface, separation of $\mathrm{Zn}$ atoms from each other due to the intrusion of Fe atoms into liquid zinc, and finally mixing between $\mathrm{Fe}$ and $\mathrm{Zn}$ atoms. Bélisle et al. ${ }^{5)}$ proposed that the bath temperature and $\mathrm{Al}$ content in zinc bath must be controlled within a close range to avoid excessive formation of intermetallics since they significantly control Fe solubility in the bath. Similar trend was predicted and also measured by McDermid et al. ${ }^{6,7)} \mathrm{O}$ 'Dell et al. ${ }^{8)}$ have proposed that Fe dissolution in zinc bath takes place in two stages - before and after the formation of inhibition layer. They have also derived the expression for $\mathrm{Fe}$ concentration in the bath, and analyzed the effects of various process parameters on Fe dissolution. Although these results and analyses give a good knowledge about iron dissolution, its transient activity at the interface, formation of the intermetallics, and the effects of some process parameters on these, very few have discussed about the effect of steel composition., ${ }^{1,9)}$ The alloying elements present in steel may affect the iron diffusivity and thus the activation energy of $\mathrm{Fe}-\mathrm{Zn}$ reactions and their kinetics. Higher amount of alloying additions are required to produce advanced high strength steels that show various difficulties in galvanizing. It is therefore worthwhile to examine this aspect. In this study, an attempt has been made to examine the effect of steel composition on iron dissolution in liquid zinc and further development of coating phases. Since iron dissolution drastically reduces with the formation of an inhibition layer, ${ }^{8)}$ no aluminum was added in the zinc bath in this study. 
Table 1. Chemical composition of steel samples (wt\%).

\begin{tabular}{|c|c|c|c|c|c|}
\hline \multirow{2}{*}{ Steel } & \multicolumn{5}{|c|}{ Chemical composition } \\
\cline { 2 - 6 } & $\mathrm{C}$ & $\mathrm{Mn}$ & $\mathrm{Si}$ & $\mathrm{P}$ & $\mathrm{Ti}$ \\
\hline $\mathrm{S}_{1}$ & 0.050 & 0.28 & 0.006 & 0.01 & 0.001 \\
\hline $\mathrm{S}_{2}$ & 0.045 & 0.45 & 0.36 & 0.036 & 0.001 \\
\hline $\mathrm{S}_{3}$ & 0.003 & 0.42 & 0.008 & 0.05 & 0.045 \\
\hline $\mathrm{S}_{4}$ & 0.003 & 0.08 & 0.008 & 0.011 & 0.074 \\
\hline
\end{tabular}

\section{Experimental}

The iron dissolution and galvanizing experiments were carried out in an alumina crucible. Four different steel compositions (namely $\mathrm{S}_{1}, \mathrm{~S}_{2}, \mathrm{~S}_{3}$ and $\mathrm{S}_{4}$ ) were selected so that the effect of different interstitial and substitutional alloying elements like $\mathrm{C}, \mathrm{Si}, \mathrm{P}$ etc. could be examined. The details of cold rolled and annealed steel strips used in the experiments are listed in Table $\mathbf{1}$.

Commercially pure zinc ( $800 \mathrm{~g}$. of $99.99 \%$ purity) was melted in the alumina crucible and held at $470^{\circ} \mathrm{C}$ for $15 \mathrm{~min}$ prior to each experiment to avoid any thermal gradient within the bath. Small test coupons $\left(45 \times 40 \mathrm{~mm}^{2}\right)$ of $1 \mathrm{~mm}$ thick steel strips were pickled in hot $\mathrm{HCl}(15 \%)$ for about $1 \mathrm{~min}$ and immediately dipped in the molten zinc for $20 \mathrm{~min}$. The liquid zinc bath was stirred by the immersed sample after every $5 \mathrm{~min}$ (i.e. after 5, 10 and $15 \mathrm{~min}$ ). For the entire experiment, the liquid zinc was maintained at $470^{\circ} \mathrm{C}\left( \pm 5^{\circ} \mathrm{C}\right)$ in a closed chamber furnace. The dipping time was decided based on the iron saturation limit in zinc and the time required to attain that. The saturation limit of iron in molten zinc can be calculated from the following equation $^{10)}$ :

$$
\ln [\mathrm{Fe}]=17.78-15388 / T
$$

where $[\mathrm{Fe}]$ is in $\mathrm{wt}^{\%} \%$ and $T$ is in Kelvin.

The saturation limit comes to be $0.053 \mathrm{wt} \%$ at $470^{\circ} \mathrm{C}$. The time required for saturation of molten zinc is in hours. ${ }^{5)}$ The dipping time was therefore chosen such that significant iron dissolution takes place without attaining saturation in order to reveal the effects of different steel compositions. At the end of dipping i.e. after $20 \mathrm{~min}$, the zinc bath was again stirred, the top dross was removed and steel test coupon was taken out of the bath quickly and air cooled. The molten zinc was cast in a sand mould. Chemical analysis of the cast zinc was carried out. This analysis has given the amount of Fe dissolved during 20 min of dipping in the molten zinc for each sample, which has been discussed in Sec. 3.1. A mixture consisting of $1 \%$ picric acid in amyl alcohol and $1 \%$ nitric acid in amyl alcohol was used as the etchant. The micro structural and energy dispersive spectroscopy (EDS) characterization of the transverse section was carried out under scanning electron microscope (SEM) for coated samples to examine the elemental distribution across the coating. The coating was mechanically ground for the X-ray analysis. The diffraction patterns were obtained using $\mathrm{CuK} \alpha$ radiation at a scan rate of $2 \% \mathrm{~min}$ in Philips Analytical X-Ray B. V. The galvanostatic studies were also carried out in an electrolyte solution $(250 \mathrm{~g} / \mathrm{L}$

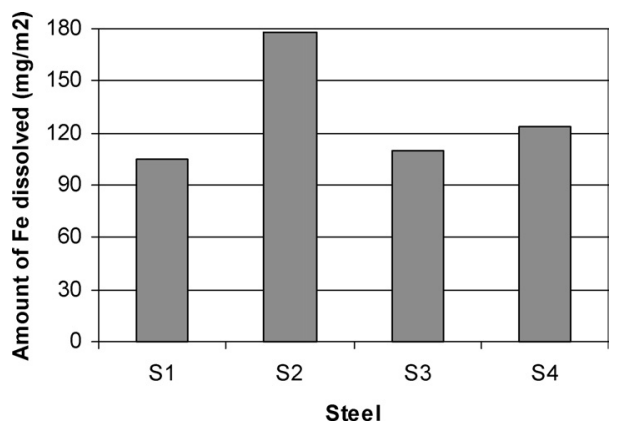

Fig. 1. Amount of Fe dissolved $\left(\mathrm{mg} / \mathrm{m}^{2}\right)$ from steel grades $\mathrm{S}_{1}, \mathrm{~S}_{2}$, $\mathrm{S}_{3}$ and $\mathrm{S}_{4}$, after $20 \mathrm{~min}$ exposure in molten zinc bath at $470^{\circ} \mathrm{C}$.

$\mathrm{NaCl}, 50 \mathrm{~g} / \mathrm{L} \mathrm{ZnSO}_{4}$ and $\mathrm{pH}$ 5) at constant current density of $15 \mathrm{~mA} / \mathrm{cm}^{2}$, using GAMRY potentiostat, for coating phase characterization. The coating, being made of layered structure of varying iron content, can be analyzed by galvanostatic method. ${ }^{10)}$ The potential time plot obtained from this method is expected to show regions representing possible $\mathrm{Fe}-\mathrm{Zn}$ phases present in the coatings. The approximate potential values obtained for various $\mathrm{Fe}-\mathrm{Zn}$ phases in galvannealed coating have been reported previously. ${ }^{10)}$

\section{Results and Discussion}

As shown in Table 1, different grades were selected such that the carbon varied from low $\left(\mathrm{S}_{1}\right.$ and $\left.\mathrm{S}_{2}\right)$ to ultra low $\left(\mathrm{S}_{3}\right.$ and $\mathrm{S}_{4}$ ) and the effects of $\mathrm{Si}$ and $\mathrm{P}$ should be reflected by steel $\mathrm{S}_{2}$ and $\mathrm{S}_{3}$ respectively. Any variation in manganese within about $1 \%$ has little effect on coating microstructure ${ }^{1)}$ and therefore its influence in the results can be ignored in the present study.

\subsection{Iron Dissolution}

The amount of iron dissolved per unit area of steel strip $\left(\mathrm{mg} / \mathrm{m}^{2}\right.$ of steel) in pure zinc bath at $470^{\circ} \mathrm{C}$ is shown in Fig. 1. This was found to be highest for steel grade $S_{2}$, followed by $S_{4}, S_{3}$ and $S_{1}$. The lower iron dissolution shown by C-Mn steel $\left(\mathrm{S}_{1}\right)$ indicates lower reactivity of steel towards the molten zinc. The main reason for low reactivity might be carbon segregation on the ferrite grain boundaries that reduced the iron diffusion through it. Similar effect of lower iron diffusion due to the presence of carbon in steel has been reported by Lin and Meshii. ${ }^{11)}$

In the present work, the highest amount of iron dissolution was shown by steel $\mathrm{S}_{2}$. It can be conceived that enhanced reactivity of steel $S_{2}$ towards molten zinc is caused 


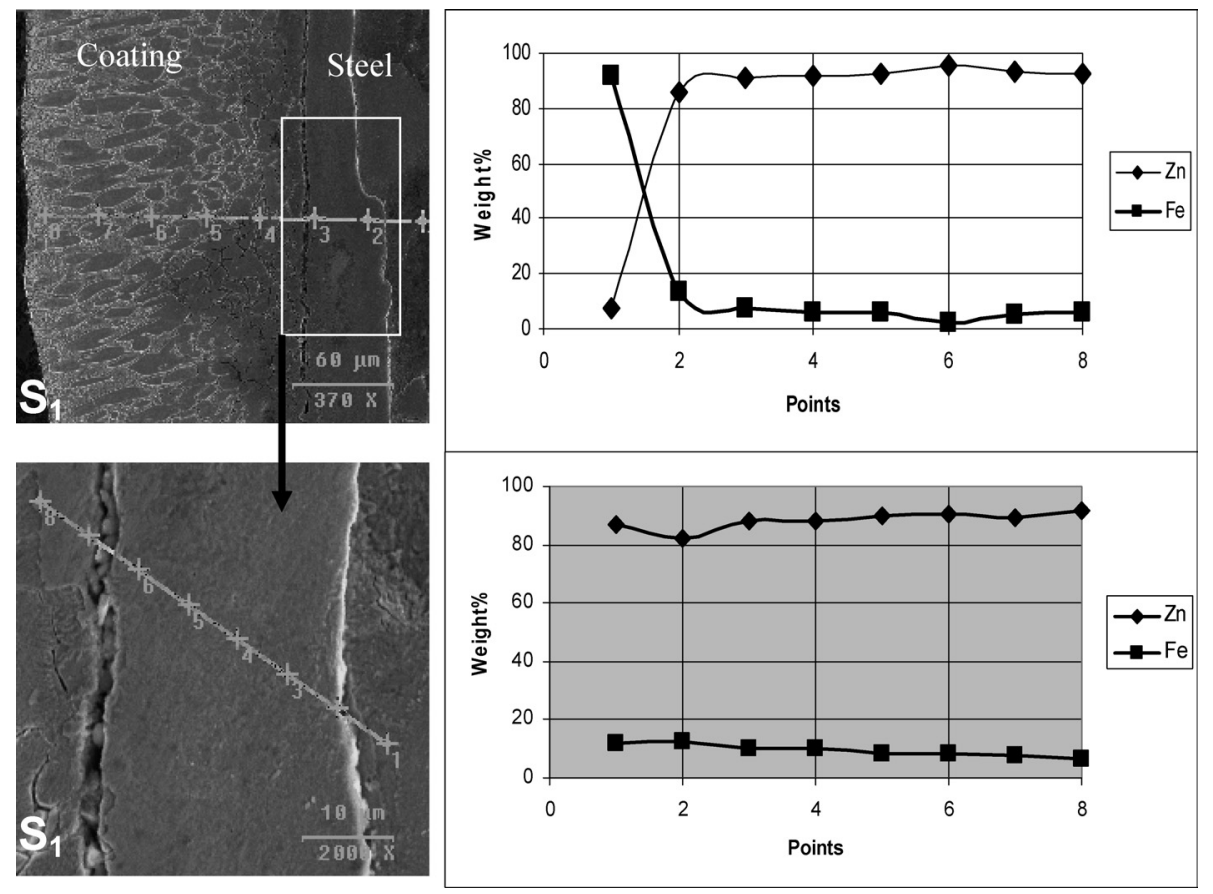

Fig. 2. EDS results of the coating obtained on steel $\mathrm{S}_{1}$.

by the presence of $0.36 \% \mathrm{Si}$. Because the steel reactivity and therefore iron solubility in molten zinc varies with silicon content in steel, ${ }^{12,13)}$ and the consequent high coating growth rate is commonly known as the Sandelin effect.

The rephosphorized interstitial free steel $\left(\mathrm{S}_{3}\right)$ showed low iron dissolution in molten zinc bath. The lower $\mathrm{Fe}-\mathrm{Zn}$ reaction kinetics shown by rephosphorized steel is well known. ${ }^{14,15)}$ According to these literature, in this ultra low carbon steel, phosphorus (like carbon in steel $\mathrm{S}_{1}$ ), segregates at the ferrite grain boundaries and hinders the path for iron diffusion leading to low iron dissolution. On the contrary, it is supposed that the higher iron dissolution shown by steel $\left(\mathrm{S}_{4}\right)$ is due to segregation free grain boundaries, which have no hindrance for iron diffusion. The excess $\mathrm{Ti}$ in Ti-stabilized interstitial free steels is calculated by following equation ${ }^{16)}$ :

$$
\begin{aligned}
\text { Excess } \mathrm{Ti}= & \text { Total } \mathrm{Ti}-3.99 \mathrm{C}-1.49 \mathrm{~S} \\
& -3.42 \mathrm{~N}-1.55 \mathrm{P} \ldots \ldots \ldots \ldots \ldots
\end{aligned}
$$

The positive value of excess Ti in steel $\mathrm{S}_{4}$ indicates that all solute atoms are tied up and thus makes the grain boundaries free from any segregation.

\subsection{Coating Characterization}

The proportion of various $\mathrm{Fe}-\mathrm{Zn}$ intermetallic phases in the coating strongly depends on the amount of iron dissolved in the molten zinc. The coating phases on various steel samples were characterized by using three different methods namely energy dispersive spectroscopy, X-ray diffraction and galvanostatic.

\subsubsection{Energy Dispersive Spectroscopy Characterization}

The SEM micrographs of the coated steel samples and their corresponding elemental profiles, (obtained for the coating from the EDS analysis) are shown in Figs. 2, 3, 4 and 5 (for sample $S_{1}, S_{2}, S_{3}$ and $S_{4}$ respectively). The point wise analysis of the coating confirms the presence of $\mathrm{Fe}-\mathrm{Zn}$ intermetallics. All the test samples have shown the presence of $\zeta$ (zeta) and $\delta$ (delta) phases in the coating. As expected, the amount of the $\mathrm{Fe}-\mathrm{Zn}$ phases in the coating varied from sample to sample. However, it was difficult to characterize any $\Gamma$ (gamma) layer in the coating. It is possible that this phase was too thin compared to the total coating thickness to be revealed by EDS point analysis.

The coating obtained on steel $\mathrm{S}_{1}$ consists of a band near interface and fine crystal network away from the interface (Fig. 2). The EDS analysis of the coating band, near steel interface has shown $7-11 \%$ Fe content, which corresponds to the $\delta$ (delta) phase. The network area has shown $6-7 \%$ Fe distributed on zinc. This confirms that the network is made up of $\zeta$ (zeta) crystals. The coating on Si added steel $\mathrm{S}_{2}$, as shown in Fig. 3, consists of thinner band of $\delta$ (delta) phase $(7-11 \% \mathrm{Fe})$ near steel interface and $\zeta$ (zeta) crystals distributed all across the coating. Apart from its high growth kinetics, the Sandelin effect is characterized by the presence of a mass of $\zeta$ (zeta) crystallites surrounded by liquid zinc in the coating structure. The typical micrograph of $\zeta$ (zeta) crystals embedded in zinc can be observed in Fig. 3(b). Due to a Si concentration gradient in liquid zinc from strip surface to the bulk and low solubility of $\mathrm{Si}$, the $\zeta$ (zeta) crystals start forming away from the steel surface, and the formation of zinc pockets between $\zeta$ (zeta) crystallites takes place. ${ }^{1,12,17)}$ Similar coating structure with the presence of overly thick $\zeta$ (zeta) crystals embedded in zinc, a thin $\delta$ (delta) layer and no $\Gamma$ (gamma) layer in a $0.37 \% \mathrm{Si}$ steel was observed by Jintang et al. ${ }^{18)}$ for higher immersion time. In rephosphorized interstitial free steel $\left(\mathrm{S}_{3}\right)$, the coating consists of mainly $\zeta$ (zeta) phase and a thin $\delta$ (delta) layer near the interface (Fig. 4). The coating obtained on $\mathrm{Ti}$ stabilized interstitial free steel $\left(\mathrm{S}_{4}\right)$ has predominantly $\delta$ (delta) phase; followed by a thin $\zeta$ (zeta) layer and zinc layer (Fig. 5).

With the help of EDS information and processing of SEM images, a comparative analysis has been done on the 

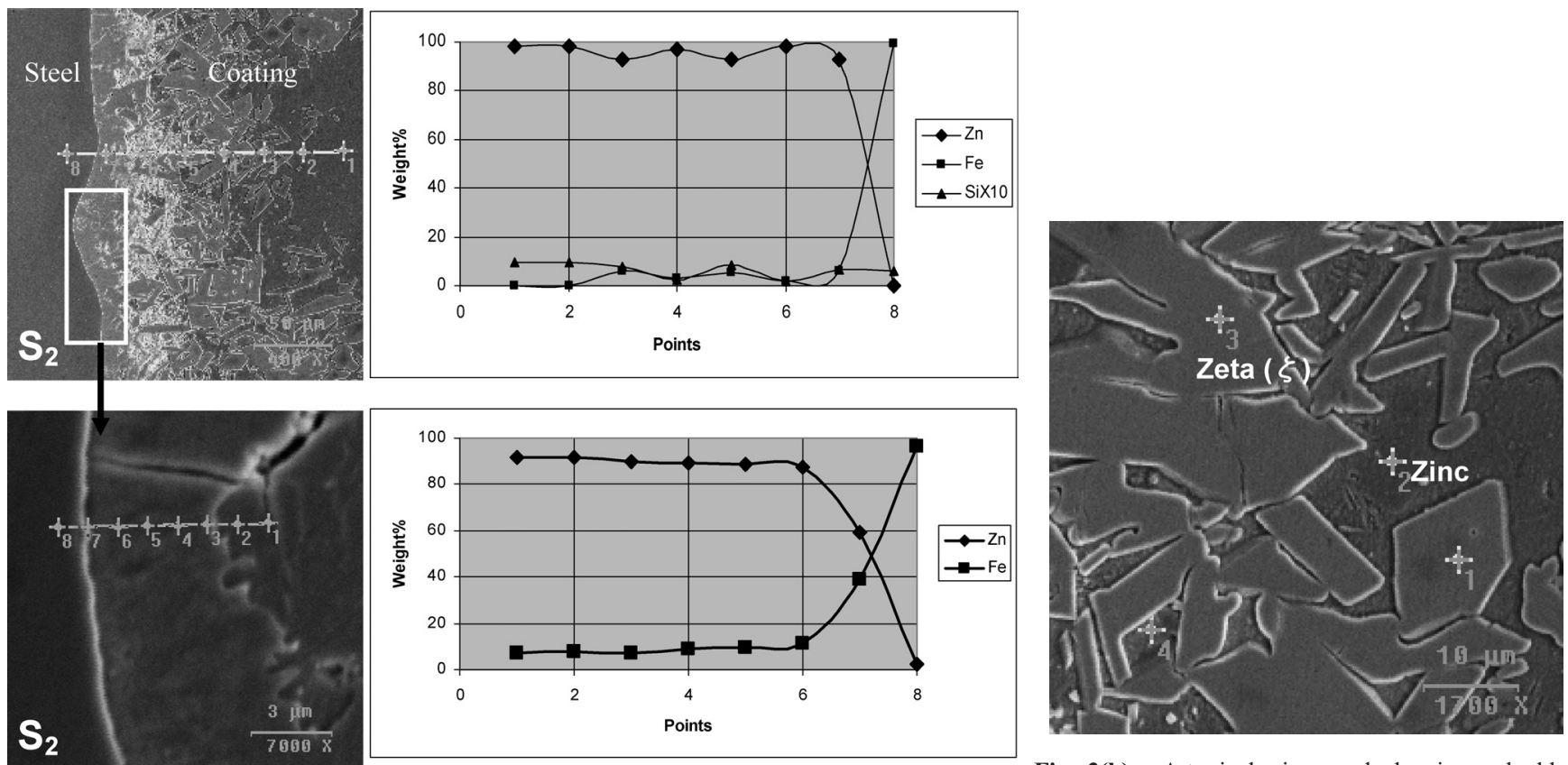

Fig. 3(a). EDS results of the coating obtained on steel $\mathrm{S}_{2}$.

Fig. 3(b). A typical micrograph showing embedded zeta $(\zeta)$ crystals in zinc.

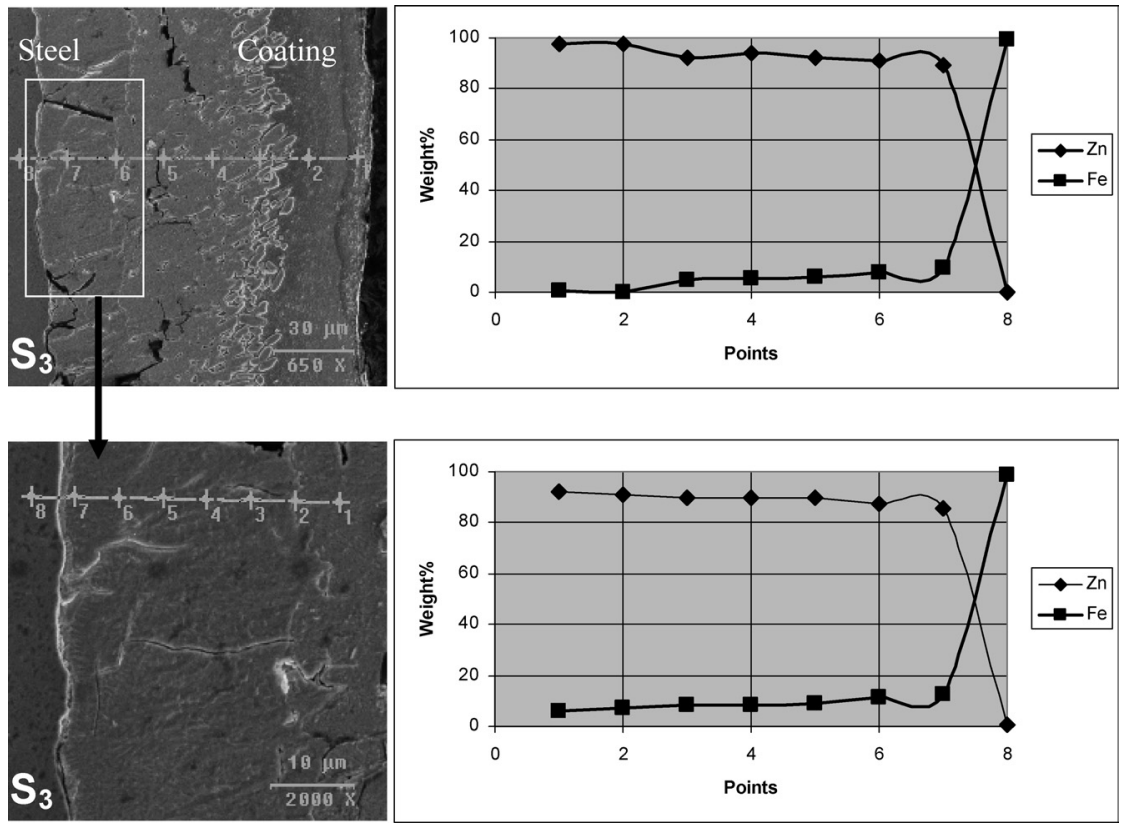

Fig. 4. EDS results of the coating obtained on steel $\mathrm{S}_{3}$.

distribution of different coating phases for different steel compositions as illustrated in Fig. 6. It is interesting to note that higher proportion of zinc is left in the coating of steel $\mathrm{S}_{1}$ and $\mathrm{S}_{3}$ which also experienced lower amount of iron dissolution and the least amount in case of steel $\mathrm{S}_{2}$ where maximum iron solubility was observed. As explained earlier, the presence of $\mathrm{Si}$ in steel $\mathrm{S}_{2}$ has increased the proportion of $\zeta$ (zeta) crystals rather than the $\delta$ (delta) phase. Although the total iron dissolution was not maximum in liquid zinc at the experimental temperature for steel $\mathrm{S}_{4}$, maximum proportion of $\delta$ (delta) phase has been resulted here. This might be the result of favorable kinetics of $\mathrm{Fe}-\mathrm{Zn}$ reaction during solidification of the coating layer due to segregationfree and reactive grain boundary, which has no hindrance for iron diffusion.

\subsubsection{X-ray Diffraction Analysis}

The intermetallic iron-zinc phases identified by XRD peaks, for coating obtained on steel $\mathrm{S}_{1}, \mathrm{~S}_{2}, \mathrm{~S}_{3}$ and $\mathrm{S}_{4}$ are listed in Table 2. Iron and Zinc peaks were identified to be commonly present for all the coatings. Therefore, they have not been mentioned in the Table 2. The diffraction patterns have identified gamma phase in the coating for steel $\mathrm{S}_{1}, \mathrm{~S}_{2}$, and $\mathrm{S}_{4}$, which could not be identified in EDS analysis. The gamma layers in the coatings were possibly very thin. However, the chemical compositions for the identified gamma phase were different for $\mathrm{S}_{1}, \mathrm{~S}_{2}$, and $\mathrm{S}_{4}$ (Table 2). The delta phase was found to be present in the coatings on all grades of steel in three different compositions. The zeta phase, of same chemical composition $\left(\mathrm{FeZn}_{15}\right)$, was also identified 


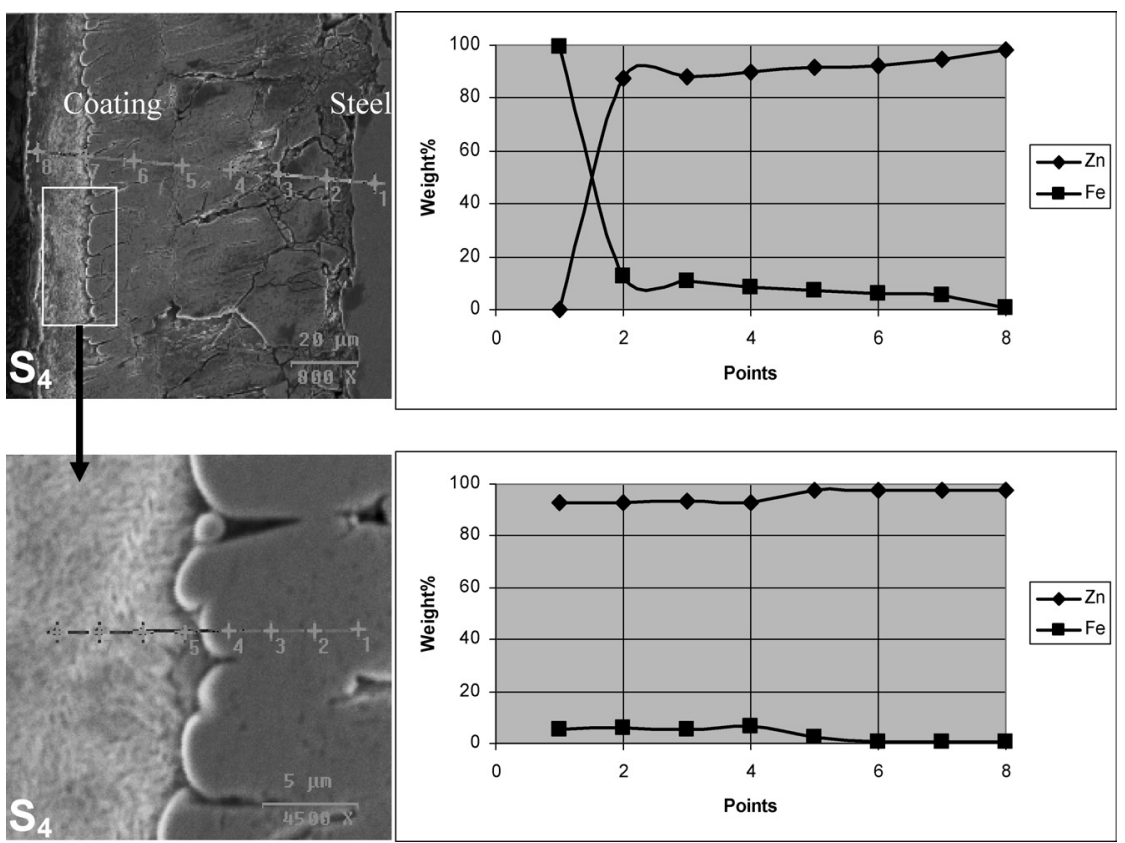

Fig. 5. EDS results of the coating obtained on steel $\mathrm{S}_{4}$.

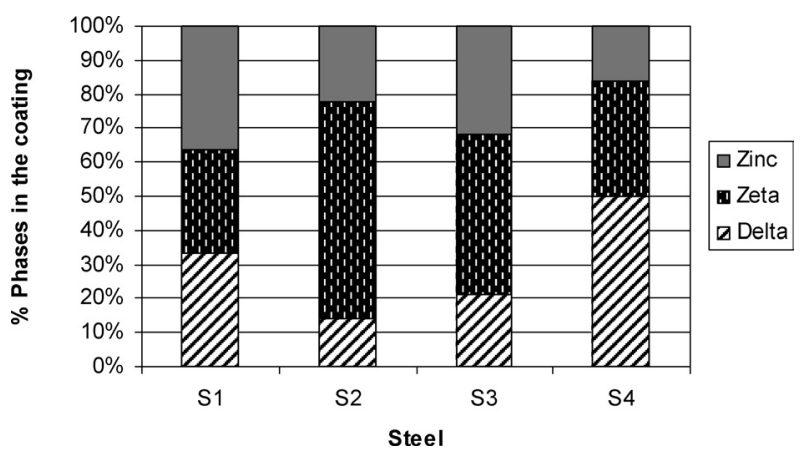

Fig. 6. Estimated distribution of coating phases for different steels.

Table 2. Coating phases identified by XRD (except Fe and $\mathrm{Zn})$.

\begin{tabular}{|c|c|c|c|c|c|}
\hline \multirow{2}{*}{$\begin{array}{l}\text { Coating } \\
\text { Phases }\end{array}$} & \multirow{2}{*}{$\begin{array}{c}\text { Chemical } \\
\text { composition } \\
\text { of phases }\end{array}$} & \multicolumn{4}{|c|}{ Presence of Coating phases identified for Steels } \\
\hline & & $\mathrm{S}_{1}$ & $\mathrm{~S}_{2}$ & $\mathrm{~S}_{3}$ & $\mathrm{~S}_{4}$ \\
\hline Zeta & $\mathrm{FeZn}_{15}$ & No & Yes & Yes & No \\
\hline \multirow{3}{*}{ Delta } & $\mathrm{FeZn}_{10.98}$ & Yes & Yes & Yes & Yes \\
\hline & $\mathrm{FeZn}_{8.87}$ & Yes & Yes & Yes & Yes \\
\hline & $\mathrm{FeZn}_{6.67}$ & Yes & Yes & Yes & Yes \\
\hline \multirow{3}{*}{ Gamma } & $\mathrm{Fe}_{11} \mathrm{Zn}_{40}$ & Yes & No & No & No \\
\hline & $\mathrm{Fe}_{4} \mathrm{Zn}_{9}$ & No & Yes & No & No \\
\hline & $\mathrm{Fe}_{5} \mathrm{Zn}_{21}$ & No & No & No & Yes \\
\hline
\end{tabular}

for coatings obtained on steel $\mathrm{S}_{2}$ and $\mathrm{S}_{3}$, which was identified by EDS analysis for all four steel grades in different proportion. The zeta phase in the coating for steel $\mathrm{S}_{1}$ and $\mathrm{S}_{4}$, being present in small amount (Fig. 6), could have been lost while mechanical grinding of the coating (for XRD sample preparation).

\subsubsection{Galvanostatic Study}

Three different approximate potential values, identified for $\mathrm{Fe}-\mathrm{Zn}$ alloys, are: zeta at $-870 \mathrm{mV}_{\mathrm{SCE}}$, delta at $-820 \mathrm{mV}_{\mathrm{SCE}}$ and gamma at $-770 \mathrm{mV}_{\mathrm{SCE}} \cdot{ }^{10)}$ The potential time plot, obtained from galvanostatic study on the coatings, has been shown in Fig. 7 for all four steel grades. The curve obtained for steel $\mathrm{S}_{1}$ and $\mathrm{S}_{2}$ shows the uniform dissolution of coating at around $-0.9 \mathrm{~V}$, indicating simultaneous dissolution of zeta phase with zinc. This potential step ranges from 3000 to $45000 \mathrm{~s}$ indicating that the coating obtained on steel $S_{1}$ and $S_{2}$ consists of a thick zeta phase and zinc. This finding is similar to EDS results (Fig. 6). The $-0.9 \mathrm{~V}$ potential step is followed by continuous positive shift in the potential indicating dissolution of delta phase. The dissolution of delta did not occur at constant value of potential which could be due to varying iron content in the delta phase. This is due to presence of delta phase of different compositions, which was also identified in the XRD analysis. Dissolution of gamma phase is characterized by potential step at around $-0.75 \mathrm{~V}$, which is shown by both $\mathrm{S}_{1}$ and $\mathrm{S}_{2}$ curves, indicating its presence in the coatings. The presence of gamma phase has also been identified for $S_{1}$ and $\mathrm{S}_{2}$ by XRD, although, it was not observed in SEM-EDS analysis as mentioned earlier. The potential step at around $-0.5 \mathrm{~V}$ indicates exposure of steel to the electrolyte, indicating that entire coating has been dissolved.

The coating obtained on steel $\mathrm{S}_{3}$ and $\mathrm{S}_{4}$ shows discrete potential steps indicating various $\mathrm{Fe}-\mathrm{Zn}$ phases, zinc and steel. Exposure of the steel to the electrolyte i.e. dissolution of entire coating has taken less time for steel $\mathrm{S}_{3}$ and $\mathrm{S}_{4}$ than $S_{1}$ and $S_{2}$ due to thinner coating on former than latter. Here again the potential step at around $-0.9 \mathrm{~V}$ symbolizes the zeta phase. After the zeta phase dissolution step $(-0.9 \mathrm{~V})$, potential increases signifying the dissolution of delta phase of varying iron content, followed by a small step at around $-0.7 \mathrm{~V}$ indicating very thin gamma phase layer. 


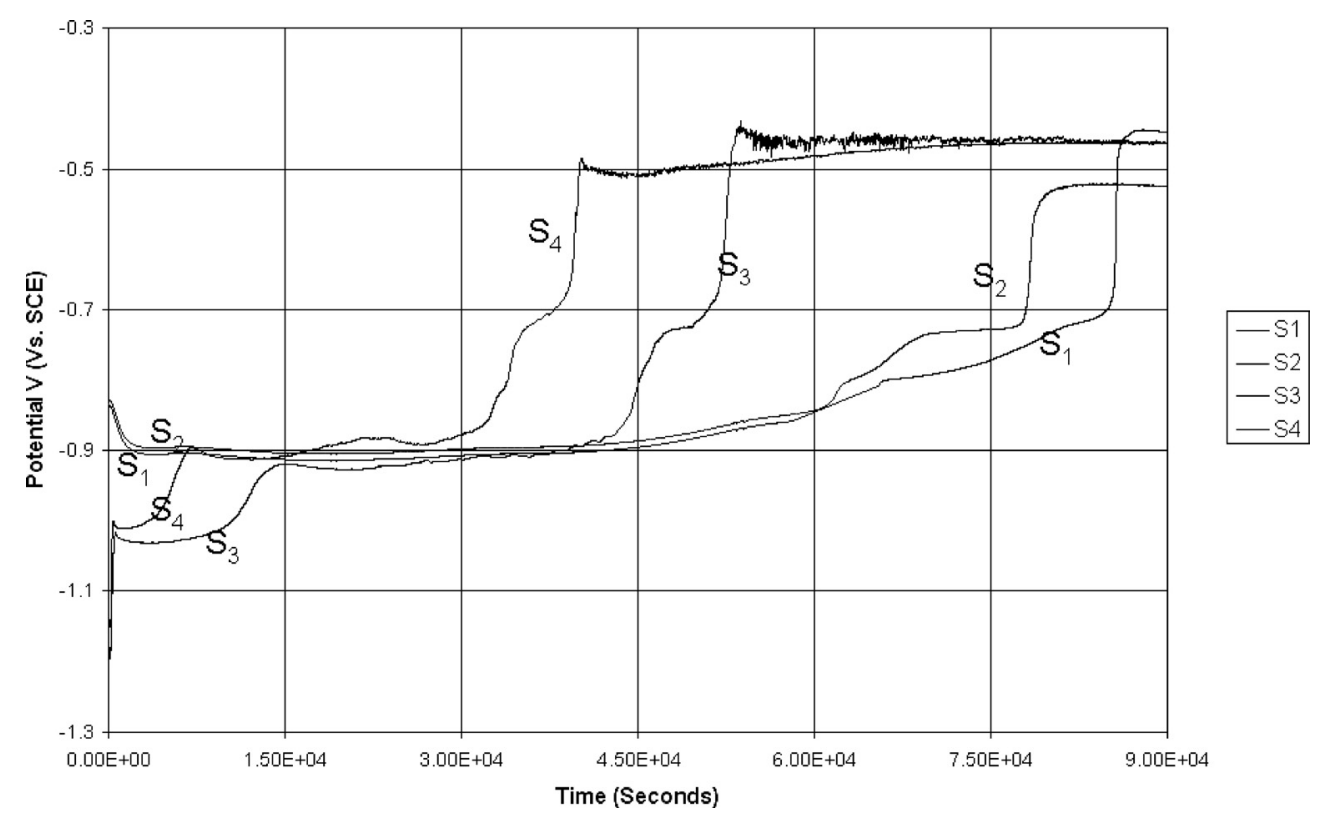

Fig. 7. Determination of coating phases by galvanostatic method at constant current density $\left(15 \mathrm{~mA} / \mathrm{cm}^{2}\right)$.

\section{Conclusions}

This study on iron dissolution by different steels in molten zinc reveals that the amount of iron dissolved in the liquid zinc and the proportion of coating phases developed on steel sheets depend upon steel compositions.

(1) The silicon alloyed steel has shown maximum iron dissolution indicating its faster reaction with molten zinc. The coating obtained on silicon alloyed steel consists of mainly $\zeta$ (zeta) crystallites embedded in zinc and thin $\delta$ (delta) layer.

(2) Similar kind of iron dissolution behaviour has been observed in C-Mn steel and rephosphorized interstitial free steel. This is due to the similar amount of hindrance caused by $\mathrm{C}$ and $\mathrm{P}$ segregation at grain boundaries towards the diffusion of iron atoms and therefore affecting the iron dissolution kinetics with similar intensity. However, their coatings differ significantly with respect to phase distribution. The C-Mn steel develops a coating band of $\delta$ (delta) phase and a network of $\zeta$ (zeta) in zinc distributed on the top of it; on the other hand, layers of $\delta$ (delta) and $\zeta$ (zeta) phases are predominant in rephosphorized interstitial free steel.

(3) Although moderate iron dissolution has been observed in interstitial free steel, the coating consists of maximum proportion of $\delta$ (delta) phase. This might be the result of favorable $\mathrm{Fe}-\mathrm{Zn}$ reaction kinetics during solidification of the coating layer due to solute-free and reactive grain boundary of steel, which has no obstruction for iron diffusion.

(4) The XRD and galvanostatic study of the coating has also revealed the presence of thin gamma layer, which could not be identified by EDS analysis.

\section{Acknowledgement}

Authors would like to acknowledge the Management of Tata Steel for giving permission to publish this work.

\section{REFERENCES}

1) J. Mackowiak and N. R. Short: Int. Met. Rev., 24 (1979), 1.

2) A. R. Marder: Prog. Mater. Sci., 45 (2000), 191.

3) Y. Leprêtre, J. M. Mataigne, M. Guttmann and J. Philibert: Zinc Based Coating Systems: Metallurgy and Performance, Conf. Proc., TMS, Warrendale, PA, (1998), 95.

4) N. Y. Tang: Zinc Based Coating Systems: Metallurgy and Performance, Conf. Proc., TMS, Warrendale, PA, (1998), 3.

5) S. Bélisle, V. Lezon and M. Gagné: J. Phase Equilibria, 12 (1991), 259.

6) J. R. McDermid and W. T. Thompson: 44th MWSP Conf. Proc., ISS, Warrendale, PA, (2002), 805.

7) J. R. McDermid, E. Baril and W. T. Thompson: GALVATECH '04 Conf. Proc., AIST, Warrendale, PA, (2004), 491.

8) S. O’Dell, J. Charles, M. Vlot and V. Randle: Mater. Sci. Techno., 20 (2004), 251.

9) S. E. Price, V. Randle and M. Pichilingi: Ironmaking Steelmaking, 26 (1999), 378.

10) H. H. Lee and D. Hiam: Corrosion, 45 (1989), 852.

11) C. S. Lin and M. Meshii: Metall. Mater. Trans. B, 25B (1994), 721.

12) J. Foct, P. Perrot and G. Reumont: Scr. Met., 28 (1993), 1195.

13) Y. Leprétre and J. M. Mataigne: Zinc-based Steel Coating Systems: Production and Performance, ed. by F. E. Goodwin, TMS, Warrendale, PA, (1998), 303.

14) Y. Hisamatsu: GALVATECH '89 Conf. Proc., ISIJ, Tokyo, (1989), 3.

15) L. Allegra, R. G. Hart and H. E. Townsend: Metall. Trans. A, 14A (1983), 401.

16) T. Toki, K. Oshima, T. Nakamori, Y. Saito, T. Tsuda and Y. Hobo: The Physical Metallurgy of Zinc Coated Steel ed. by A. R. Marder, TMS, Warrendale, PA, (1994), 169.

17) X. Su, N.-Y. Tang and J. M. Toguri: Can. Metall. Q., 40 (2001), 377.

18) J. Lu, C. Che, G. Kong, Q. Xu and J. Chen: Surf. Coat. Technol., 200 (2006), 5277. 